\title{
- \\ Re: Endourologic strategies for a minimally invasive management of urinary tract stones in patients with urinary diversion
}

\author{
Ines Mendes Pina ${ }^{1}$, Michael S. Floyd Jr. ${ }^{1}$, Simon R. Stubington ${ }^{2}$ \\ ${ }^{1}$ Department of Reconstructive Urology, St Helens \& Knowsley Hospital NHS Trust, United Kingdom, \\ UK; ${ }^{2}$ Department of Urology, Michael Heal Unit, Mid Cheshire Hospital NHS Foundation Trust, United \\ Kingdom, UK
}

To the editor,

We read with interest the recent paper by Zhong et al. examining the variety of endourological strategies available for the management of urinary tract stone disease in patients following urinary diversion (1).

The authors report a retrospective study involving 26 patients who underwent urinary diversion and who subsequently presented with stone related problems and allude to the variety of techniques available (1).

Specific to the lower tract it is stated that 3 patients underwent orthotopic neobladder surgery and were subsequently treated for vesical calculi with neobladder lithotripsy and in select cases a second look procedure was performed 3-5 days later (1).

The authors list the treatment modalities mentioned: PCNL, SWL, Percutaneous antegrade and retrograde ureteroscopy and open removal (1) but should acknowledge that in the diverted patient a variety of hybrid techniques have evolved to permit safe lower tract stone removal. Specific to the neuropathic patient with an ablated urethra and Mitrofanoff bladder laser cystolithotripsy with a flexible cystoscope (Leighton Technique) allowing complete stone removal in one sitting has been described (2). In the paediatric patient with an augmented bladder a separate hybrid technique involving endoscopic and laparoscopic approaches with preoperative lithotripsy has also been described (3). In patients with stone disease in a continent diversion another hybrid technique involving laparoscopic entrapment and fragmentation with conventional lithotripsy has been documented (4). The Mini PCNL technique has also been adapted for use in a spinal patient with an ablated urethra to achieve stone removal via a Mitrofanoff tract (5).

\section{CONFLICT OF INTEREST}

None declared. 


\section{LETTER TO THE EDITOR}

\section{REFERENCES}

1. Zhong F, Alberto G, Chen G, Zhu W, Tang F, Zeng G, et al. Endourologic strategies for a minimally invasive management of urinary tract stones in patients with urinary diversion. Int Braz J Urol. 2018;44:75-80.

2. Floyd MS Jr, Stubington SR. Mitrofanoff cystolitholapaxy: an innovative method of stone clearance in a hostile abdomen with an inaccessible urethra. Urol J. 2015;12:2115-8.

Submitted for publication:

March 11, 2018

Accepted after revision:

March 14, 2018

Published as Ahead of Print:

April 10, 2018
3. Miller DC, Park JM. Percutaneous cystolithotomy using a laparoscopic entrapment sac. Urology. 2003;62:333-6.

4. Jarrett TW, Pound CR, Kavoussi LR. Stone entrapment during percutaneous removal of infection stones from a continent diversion. J Urol. 1999;162(3 Pt 1):775-6.

5. Floyd, MS., Sakalis, V., Davies, MC. Mitrofanoff cystolitholopaxy and bladder biopsy using a mini-PCNL kit. J Clin Urol. 2017;10:36-8.
Correspondence address:

Ines Mendes Pina, MD

Department of Reconstructive Urology St Helens \& Knowsley Hospital NHS Trust

Whiston Hospital

Warrington Road Prescot L35 5DR United Kingdom, UK

E-mail: pina_ines@hotmail.com

ARTICLE INFO

Int Braz J Urol. 2018; 44: 846-7 